\title{
THE IMPACT OF ROAD PAVEMENT ON URBAN HEAT ISLAND (UHI) PHENOMENON
}

\author{
Siti Halipah Ibrahim ${ }^{1 *}$, Nurul Izzati Ahmat Ibrahim ${ }^{1}$, Julaihi Wahid ${ }^{1}$, Nurakmal Abdullah Goh ${ }^{1}$, \\ Dona Rose Amer Koesmeri ${ }^{1}$, Mohd Nasrun Mohd Nawi ${ }^{2}$ \\ ${ }^{1}$ Department of Civil Engineering, Faculty of Engineering, Universiti Malaysia Sarawak (UNIMAS), \\ Jalan Datuk Mohammad Musa, 94300 Kota Samarahan, Sarawak \\ ${ }^{2}$ School of Technology Management and Logistic, Universiti Utara Malaysia, \\ 06010 Sintok, Kedah, Malaysia.
}

(Received: July 2018 / Revised: September 2018 / Accepted: December 2018)

\begin{abstract}
An urban heat island (UHI) is a climatic phenomenon caused by modifications to the climate due to changes in the form and composition of the land surface and atmosphere. The aim of this study is to investigate the impact of road pavement types for mitigating or intensifying UHI. This study was conducted in the Kota Samarahan area. Since Kota Samarahan is classified as a suburban area, it is still a developing district. Hence, there is still an opportunity for proper planning, such as choosing the most suitable type of pavement, before this area becomes a UHI. Data was collected by studying four types of pavements (asphalt, concrete, permeable, and industrialised building system (IBS) StormPav) in terms of their characteristics, performance, and maintenance costs. Additionally, their surface temperatures were investigated using ThermaCam and then plotted against the surrounding air temperature. Interview sessions were also conducted with the personnel of Jabatan Kerja Raya to obtain valuable information for this research. As a result, this study found that the construction of asphalt pavement can produce numerous potential impacts on the environment, which further contribute to air pollution and the UHI effect. Concrete, permeable, and IBS StormPav pavements retained less heat compared to asphalt, and can be implement to mitigate the UHI phenomenon. Furthermore, the implementation of green walls, cool roofs, vegetation and trees, and altering the properties and construction of asphalt pavement can help in mitigating this phenomenon.
\end{abstract}

Keywords: Air temperature; Pavement; Surface temperature; Urban heat island (UHI)

\section{INTRODUCTION}

The phenomenon known as an urban heat island (UHI) often forms in urban and suburban areas where the surface temperature and air are hotter than the rural surroundings. A heat island is also known as a reverse oasis. This phenomenon has been found in many cities worldwide and is growing. In 1818, Luke Howard's study of London's climate was the first documented UHI (Gartland, 2012). He found that the city had artificial heat in comparison to the country. Similar discoveries were made by Emilien Renou about Paris during the second half of the $19^{\text {th }}$ century.

This phenomenon is seen as a negative factor in thermal comfort. The UHI phenomenon is

\footnotetext{
*Corresponding author's email: ihalipah@unimas.my, Tel. +6082-592611, Fax.+082-5821140 Permalink/DOI: https://doi.org/10.14716/ijtech.v9i8.2755
} 
simply the storage of solar energy during daytime (Katzschner, 2009), which would normally be released into the atmosphere at night. Heat islands are common in urban and suburban areas due to the concentrations of structures and pavement. The structures are typically composed of materials such as concrete that can retain and absorb higher amounts of heat from the sun than the natural materials utilized in rural areas (Gartland, 2012). Furthermore, the dark materials in concert with canyon-like configurations of pavement and buildings further contribute to the absorption of heat. When vegetated surfaces with moist soil underneath are exposed to direct sunlight, the temperature of the heat absorbed is only around $18^{\circ} \mathrm{C}$ (Gartland, 2012). However, the temperatures absorbed by dark and dry surfaces exposed to the same conditions can reach up to $52^{\circ} \mathrm{C}$ (Ibrahim et al., 2014). Waste heat from human activity also exacerbates this phenomenon. Some of the most notable sources of waste heat are air conditioners and emissions from vehicle engines.

The paved surfaces in urban and suburban areas are often warmer than the less-paved surfaces in rural areas. Pavement is usually comprised of materials with very low reflectivity or albedo. Albedo is defined as the fraction of the incident radiation that is reflected from a surface (Dobos, 2003). It plays a significant role in the energy balance on the surface of the earth since it defines how much solar radiation is absorbed.

Surfaces generally absorb most of the radiation that comes into contact with them (Calkins, 2012). This heats up the pavement material and the heat is then reradiated, elevating the surrounding ambient air temperatures. In pavement structures, the only surface which affects albedo is the topmost layer. Hence, if heat generation is a concern, albedo should be taken into consideration when selecting a pavement type. The two most commonly used pavements worldwide are hot mix asphalt (HMA) and Portland cement concrete (PCC) pavements. Permeable pavement is also commonly used in urban areas, usually in sidewalks and parking lots.

The balance between increased air temperature caused by solar energy (heating process) and decreased air temperature due to evaporation (cooling process) is altered by urbanization and development. Figure 1 shows the normal heat island profile for a city. The figure illustrates how the temperature increases from the rural fringe and peaks in the city center. The varying temperatures across the city are influenced by the nature of the land cover (Katzschner, 2009). The lakes and urban parks are noticeably cooler than the areas with a high concentration of buildings.

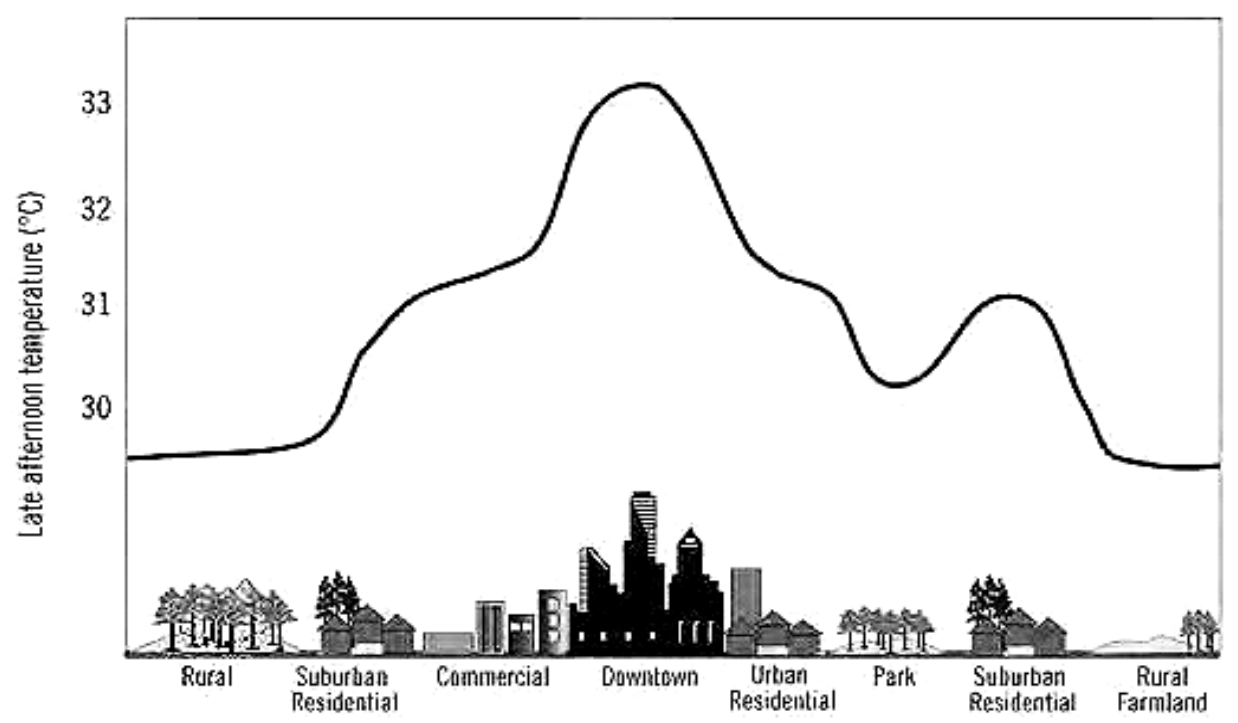

Figure 1 UHI profile (Katzschner, 2009) 
Not only does the UHI increase the daytime temperature and reduce nighttime cooling, it is also associated with air pollution. This phenomenon leads to increased energy demand for air conditioning, which releases more heat as well as greenhouse gas emissions into the air (Rosenfeld et al., 1995). Therefore, the local air quality is degraded. Additionally, human health can also be affected by air pollution, leading to respiratory difficulties, heat cramps, non-fatal heat stroke, and general discomfort $(\mathrm{Li}, 2015)$. Sensitive populations such as older adults and children have the highest risk for these negative health effects.

In comparison to the rural surrounding areas, the urban areas have higher temperatures. The man-made land formed by development activities in an urban area can increase the environmental temperature by $0.5-1.5^{\circ} \mathrm{C}$ (Brontowiyono et al., 2011). The modification of land surfaces using materials such as asphalt and concrete are considered to be the main factors that influence the environmental temperature and surface energy balance in urban areas. Generally, pavements have relatively high solar energy absorption because they possess a higher heat storage capacity. They tend to absorb heat during the day and then slowly release it back into the atmosphere at night (Katzschner, 2009).

Asphalt pavement and other dark surfaces in urban environments are the primary causes of the UHI (Calkins, 2012). The asphalt pavement absorbs the radiation of the sun rather than reflecting it, increasing the temperature of ambient air and pavement surfaces. The temperature of the asphalt pavement can reach up to $50^{\circ} \mathrm{F}$ higher than a reflective white surface, making the heat from the pavement unbearable. Figure 2 shows the daily temperature of a street located in Phoenix, Arizona, USA. It has been shown that a 1 -second exposure to $70^{\circ} \mathrm{C}$ pavement can cause burns to the skin (American Concrete Pavement Association, 2009). At this temperature, an egg can cook on the surface of the pavement in just 5 minutes.

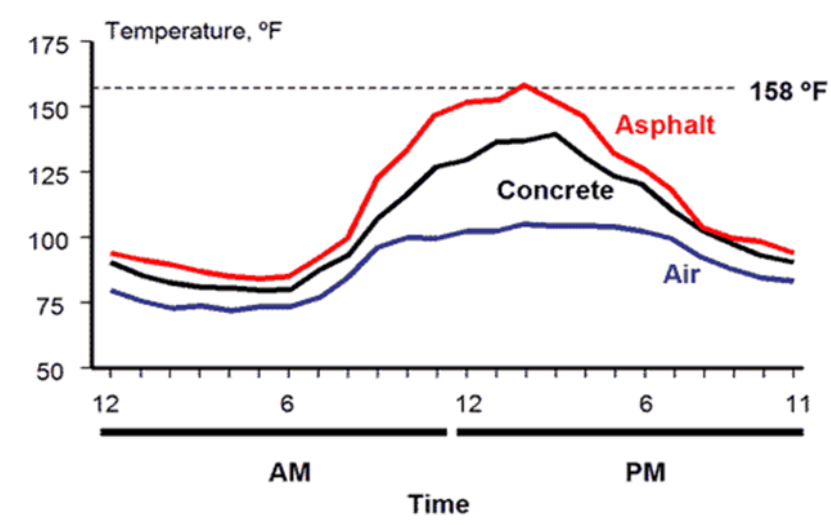

Figure 2 Daily temperature of a Phoenix street (American Concrete Pavement Association, 2009)

Numerous theoretical and experimental studies have suggested that paved surfaces play a significant role in increased urban temperatures and declining ambient quality. A case study conducted by Rose et al. (2003) in Greater Houston, Texas concluded that 29\% of the cities in that area are covered by paved surfaces. Another study conducted in metropolitan Chicago, Illinois by Akbari and Rose (2001) indicated that sidewalks, roads, and parking areas cover about $29-39 \%$ of the city when viewed from above the urban canopy and 36-45\% when viewed from below the urban canopy. Various experimental studies conducted worldwide have also concluded that one of the main contributors to the UHI phenomenon is pavement (e.g., Asaeda et al., 1996). Therefore, it is crucial to study the pavement types and characteristics and how these contribute to the intensification or mitigation of this phenomenon. 


\section{EXPERIMENT}

The data on the surface temperatures of different types of pavements were collected by using ThermaCAM P65 (FLIR Systems, Inc, Oregon, United States) as shown in Figure 3. The surface temperatures of the pavements were collected from 6:00 am to 6:00 pm. In addition, the hourly air temperatures were collected using an anemometer, model AM-4205A (Lutron Electronic Enterprise Co., Ltd., Taipei, Taiwan) (see Figure 4). It can be used to measure air velocity, air temperature, and relative humidity. Both east and west campus of Universiti Malaysia Sarawak areas were included in the data collection.

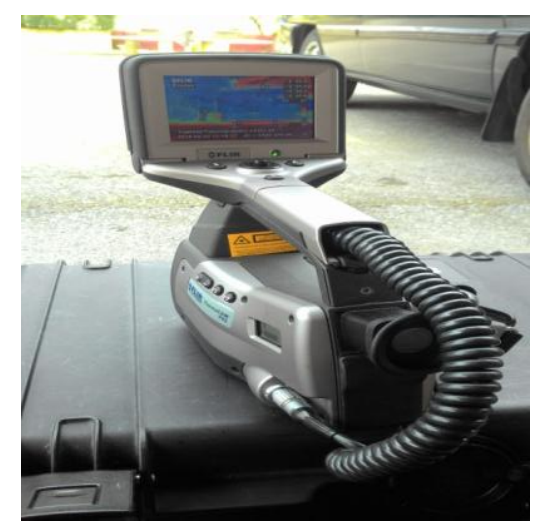

Figure 3 ThermaCAM P65

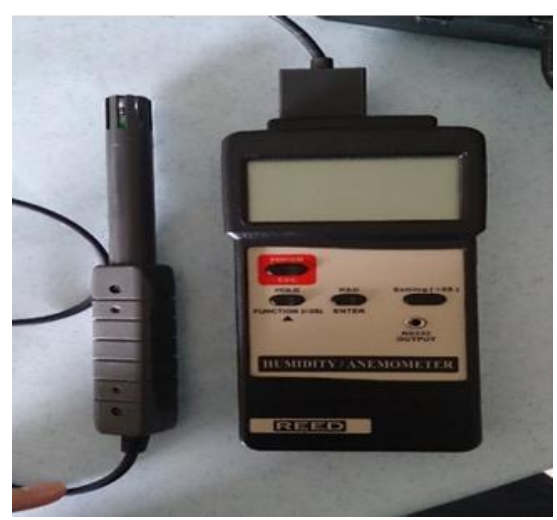

Figure 4 Anemometer AM-4205A

HMA pavement was compared with each of the other types of pavements in order to prove that asphalt or flexible pavement and other dark surfaces are the main contributors to heat islands. Figure 5 shows the surface temperature of honeycomb pavement compared with that of asphalt pavement. These pavements are located near Civil Engineering Laboratory on the west campus. Figure 6 shows the comparison between the surface temperatures of permeable and asphalt pavements, and Figure 7 shows the surface temperature comparison between concrete and asphalt pavements. All pavements were marked with black tape to ensure the data were collected near the same spot every time. Interview sessions were conducted with some of the personnel of Jabatan Kerja Raya Sarawak that are actively involved in the management, design, construction, operation, and maintenance sectors of road development in Sarawak to obtain additional and valuable information for this research.

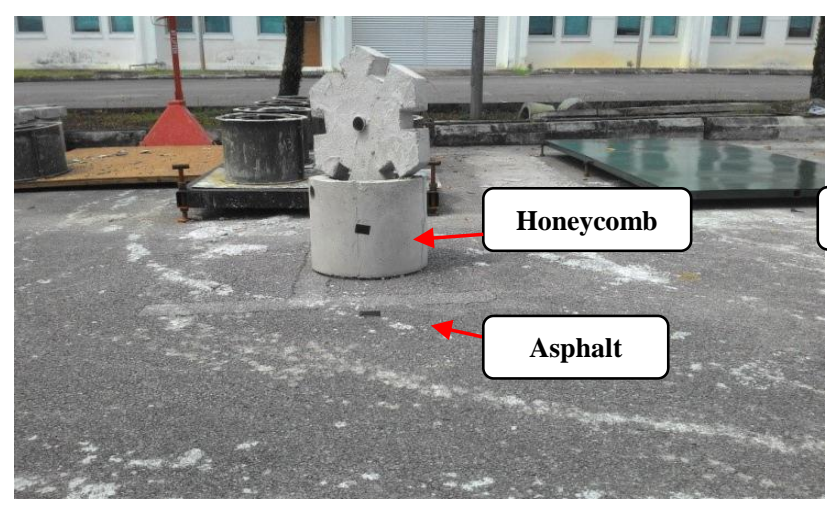

Figure 5 Asphalt and honeycomb pavements

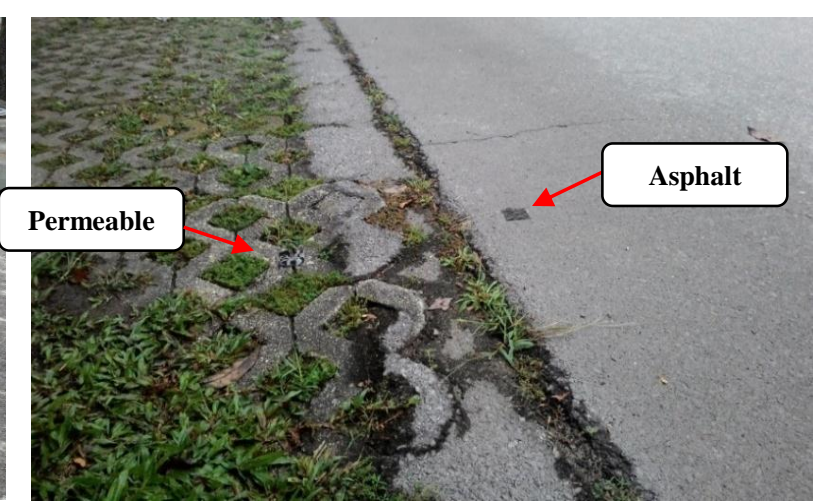

Figure 6 Asphalt and permeable pavements 


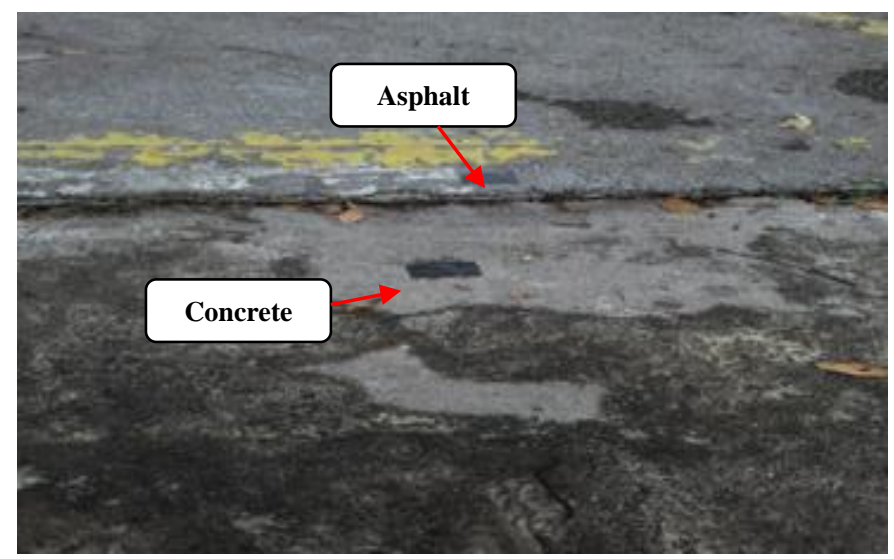

Figure 7 Asphalt and concrete pavements

\section{RESULTS AND DISCUSSION}

\subsection{Surface Temperatures of Pavements}

The surface temperatures were collected hourly for 12 hours. The data collection was conducted from 6:00 am to 6:00 pm. Then, the collected air temperature (dry bulb temperature) was plotted alongside the surface temperature of the pavements. Figures 8 and 9 show the surface temperatures for Day 1 and Day 2 of data collection, respectively. All types of pavements are plotted together in one graph for comparison.

For the first day of data collection (Figure 8), it can be seen that asphalt absorbed the most heat, followed by concrete pavement. IBS StormPav (Universiti Malaysia Sarawak, Kota Samarahan, Sarawak and Jabatan Kerja Raya, Kuching, Sarawak) absorbed less heat than asphalt and concrete pavements, but it was certainly higher than that of permeable pavement, which absorbed the least heat compared to the other types. This is because the concrete pavement has a lighter color, which reflects solar radiation rather than absorbing it. Black concrete surfaces tend to be hotter than reflective white surfaces.

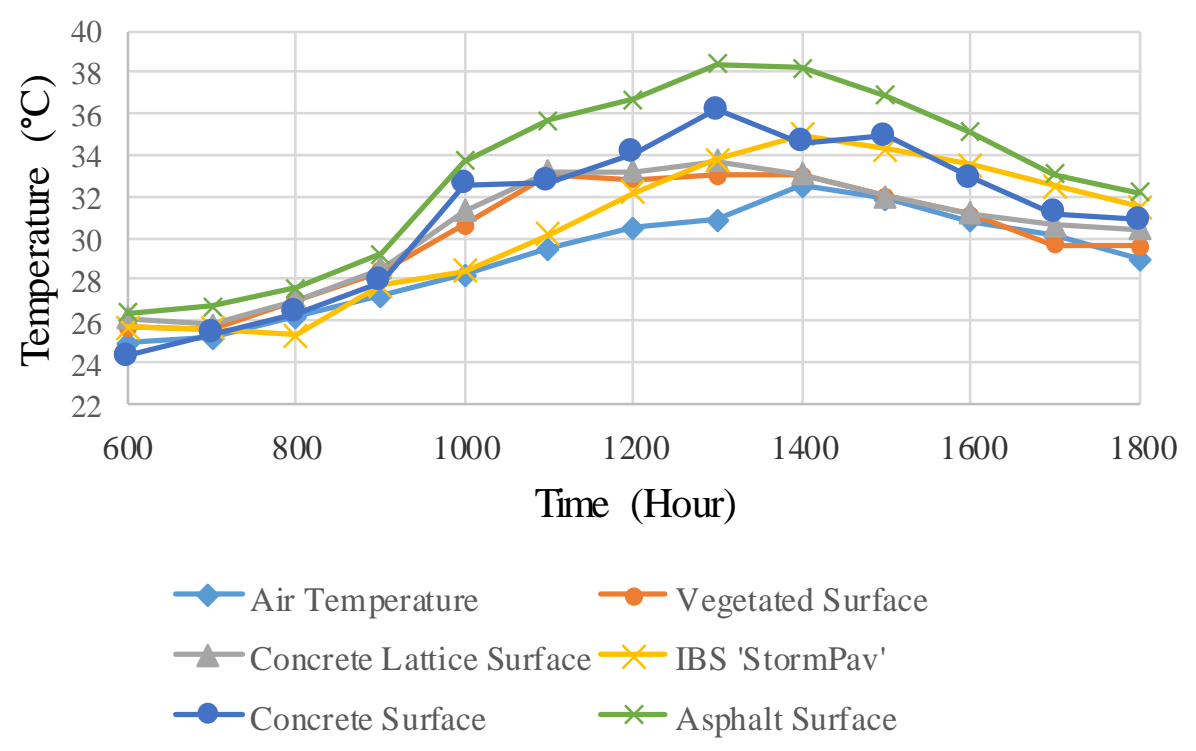

Figure 8 Time vs. surface temperature for all types of pavement, Day 1

For the second day of data collection (Figure 9), the asphalt pavement retained more heat than the concrete pavement. Once again, the IBS StormPav pavement absorbed less heat than the asphalt pavement. However, on this day, the highest surface temperature for the permeable 
pavement was higher than for the concrete pavement. However, the temperature difference was small, with a difference of only $1.7^{\circ} \mathrm{C}$. The maximum surface temperature of the permeable pavement was still lower than that of asphalt since the permeable pavement permits water to filter into the ground, which help to keep the pavement temperature low when moist. This pavement can also undergo higher convective losses since it has a greater surface area in contact with the air compared to dense pavements.
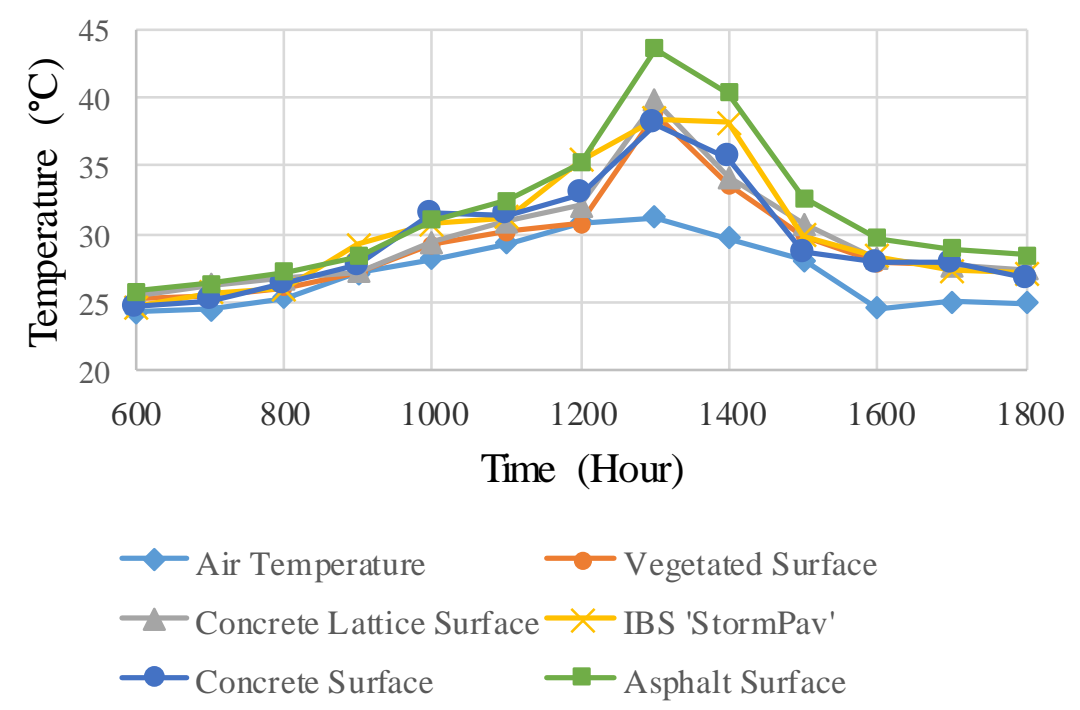

Figure 9 Time vs. surface temperature for all types of pavement, Day 2

During the on-site data collection, the main factor that altered the thermal performance of the pavement surfaces was solar radiation. The results show that the pavements' surface temperatures were notably higher at noon and 1:00 pm. The maximum air temperature reached approximately $32.5^{\circ} \mathrm{C}$. These conditions are representative of the tropical climate in the case study area. This further proves that the surface temperature of the pavements is directly proportional to the solar intensity. The surface temperatures of the pavements were highest in the early afternoon (around 1:00 pm) because during this time, the solar intensity is normally at its peak. During early morning and late evening, the surface temperatures of the pavements are lower than noon time because the solar intensity is at its lowest during these times. The data also show that the energy budget of the near surface atmosphere or air temperature depends on the pavement's surface temperature which undergone the thermal processes below the surface, also known as thermal balance.

The thermal balance of pavement is associated with the amount of retained (i.e., absorbed and stored) solar radiation, released infrared radiation, heat transferred via convection to the atmospheric air, heat collected in the mass of material, and heat conducted to the ground (Santamouris, 2013). Evaporation and condensation also affect the thermal regime of pavement surfaces, affecting latent heat phenomena. Anthropogenic heat (i.e., heat due to road traffic) may also affect the thermal balance of the road materials.

The surface temperature of asphalt is higher than that of other pervious paved surfaces or natural grass. This is explained by the effect of the water content and net heat flux at the surface of nonporous pavement, which is used for heating the pavement's surface layer. Due to evapotranspiration from grass surface, the temperature of natural grass surfaces is lower than that of other surfaces (Sarat \& Eusuf, 2012). Around noon, the surface temperature of natural grass decreases rapidly. Therefore, the grass surface cools the atmosphere at night. This is 
because unlike asphalt and concrete, grass does not store incoming solar radiation but reflects most of it.

In contrast, since the surface temperature of asphalt pavement is always greater than the air temperature, the near atmosphere is always being heated. This is due to the inability of asphalt to allow evaporation to take place, which results in thermal discomfort (Sarat \& Eusuf, 2012). Generally, factors in the nearby environment, such tree shade, evapotranspiration and evaporation from plants, anthropogenic heat, and man-made objects impact the urban thermal environment (Lin et al., 2010). The type of ground surface, such as artificial pavement and natural grass, also affect the thermal environment.

The amount of solar radiation reflected from the surface of the pavement is affected by its albedo. Pavement with a low albedo value, such as asphalt, is one of the main contributors to high air temperatures and thermal discomfort. Surface temperature is dependent on absorption degree. If the absorption rate of one pavement type is higher than other types, the surface of the former will be hotter. Studies conducted by Juliet and Ossen (2009) revealed that around noon, more than $350 \mathrm{~W} / \mathrm{m}^{2}$ and $600 \mathrm{~W} / \mathrm{m}^{2}$ of sensible heat and longwave radiation, respectively, were released from the asphalt pavement surfaces to the atmosphere. Additionally, asphalt pavement's surface temperature can reach up to $55^{\circ} \mathrm{C}$. The air is directly heated by the sensible heat. This further proves that asphalt pavement absorbs the most heat compared to the other pavement types and reaches its peak at noon.

Meanwhile, the thermal load on pedestrians is increased by the upward longwave radiation, which causes great thermal discomfort. Heated concrete can also cause significant thermal discomfort to pedestrians. The increment in the surface temperature of the impermeable pavement is due to the deficiency of evaporation, which consumes a large portion of net radiation to the surface, and at its peak around noon can be as high as $400 \mathrm{~W} / \mathrm{m}^{2}$. The extensive evaporation and lower albedo value of permeable pavement caused vegetated surface temperatures to always be lower than other pavement surfaces in the case study area. Hence, pavements which enable the exchange of water between the pavement and the underlying soil, enabling the evaporation process to take place at the ground surface, is desirable in helping to reduce the heat island phenomenon.

Porous (or permeable) pavement permits water to filter into the ground; therefore, it keeps the whole pavement at a lower temperature when moist. This pavement will also undergo higher convective losses due to its greater surface areas in contact with the air compared to dense pavements. Its ability to collect water moisture helps in accelerating heat loss from evaporation. Hence, this pavement retained less heat than the other three types of pavements. IBS StormPav pavement is composed of G50 concrete. Hence, it possesses the characteristics of normal concrete pavement. Since it is capable of providing storm water retention of 3 hours 10 -year average recurrence interval design rainfall and is directly installed on the subgrade, it could hold a high amount of storm water as well as promoting effective infiltration process, keeping the underneath soil moist. Hence, its surface temperature can be lower than that of normal concrete pavement. However, concrete pavement will always have a lower surface temperature than asphalt. This is due to its lighter color, which reflects the solar radiation rather than absorbing it, like asphalt. Black surfaces tend to be $21^{\circ} \mathrm{C}$ hotter than reflective white surfaces (Delatte, 2007).

In terms of the thermal properties of pavement material, asphalt has a higher thermal conductivity of $1.2 \mathrm{~W} / \mathrm{mK}$, compared to PCC's thermal conductivity of $1.1 \mathrm{~W} / \mathrm{mK}$ (Stempihar et al., 2011). Obviously, asphalt absorbs more heat than the other types of pavements. Besides that, the albedo of asphalt is lower than that of PCC, at 0.1 and 0.25 , respectively. Since asphalt has a higher density $\left(2238 \mathrm{~kg} / \mathrm{m}^{3}\right)$ compared to concrete $\left(2100 \mathrm{~kg} / \mathrm{m}^{3}\right)$, asphalt will absorb more 
heat. The denser the material, the higher amount of heat it will retain.

\subsection{Performance of Pavements}

The performance and characteristics of all pavements reviewed in the literature were studied, and also interview sessions with JKR personnel were conducted. The literature and interviews confirmed that the majority of road construction utilizes asphalt pavement over any other type. Concrete is rarely used for highways. Both pavements are constructed based on the Standard Specification for Road Works by Jabatan Kerja Raya (1988). Currently, there are no approaches being implemented in any road construction to decrease or prevent the UHI phenomenon in Malaysia.

Every type of pavement requires maintenance from time to time in order to ensure high performance and safety for users. In flexible pavement, maintenance is needed for defects such as wheel ruts, potholes, and shrinkage cracks (American Association of State Highway and Transportation Officials, 2007). Flexible or asphalt pavement is widely used in Sarawak. Asphalt pavement, once known as asphalt concrete pavement, is composed of a mix of coarse and fine aggregates bounded by asphalt cement. It is comprised of the heavy hydrocarbon that remains after lighter fractions have been extracted from crude oil. This type of pavement is used in $90 \%$ of new roads (Swee, 2016). Furthermore, the thicker the pavement, the higher its strength. Hence, the strength of the pavement depends on the design itself. Estimating the equivalent single axle load that a specific pavement will encounter over its life is a basic element in pavement design (Ping, 2016).

Maintenance of asphalt pavement, such as resurfacing, is usually done once every five years (Ping, 2016). However, if the road condition is poor or unsafe for public use, resurfacing may be done immediately. Once a year, an annual road condition survey is conducted by JKR to check on all road conditions and assign condition ratings. Road maintenance is usually done by Perbadanan Pembangunan Ekonomi Sarawak (PPES) Works, CMS, and other private or contractor companies hired by JKR.

Asphalt pavement construction can impact the environment by contributing to the UHI effect (Calkins, 2012). First, during mixing in the plant, energy is required in the production of HMA to heat the aggregate and binder to temperatures ranging from $121.1^{\circ} \mathrm{C}$ to $176.6^{\circ} \mathrm{C}$. The aggregate and binder is kept heated as it is transported to the site and also during pavement. The emissions and fumes released from the mixing, heating, and placement of asphalt concrete then negatively impact the air quality and human health. Second, asphalt pavement is made from non-renewable petroleum and aggregate resources.

From the interviews conducted, concrete or rigid pavement is rarely used in Sarawak due to the cost of construction and materials. It is only implemented in walkways or pedestrian pathways but not in main roads. However, in terms of cost-effective investments, concrete highways have an excellent track record (Cement Association of Canada, 2007). Rigid concrete pavement has less impact on the environment and outperforms asphalt pavement in terms of safety and economic benefits. Less maintenance is required for concrete pavement over its lifetime and it lasts longer than asphalt pavement. Maintenance for rigid pavement is needed for defects such as joint failure, longitudinal cracks, and transverse cracks. Its rigid nature provides a stable surface that is protected from shove, rut, or washboard. This pavement also minimizes the potential for potholes.

Permeable pavement is also rarely used in Sarawak for highways (Swee, 2016), though it is commonly used in parking areas. Compared to conventional pavement, permeable pavement is considered to be a safer surface. Permeable pavement promotes better traction than conventional pavement (Virginia Water Resources Research Center, 2011). Besides that, it exhibits less risk of hydroplaning. The maintenance of permeable pavement is relatively 
minimal after installation but absolutely necessary to ensure the system's longevity. The main drawback of grass paving is its cost, which is higher than concrete and asphalt. A parking area with $20 \%$ grassed paving will cost approximately $60 \%$ more money for installation than asphalt given the same conditions (Thompson \& Sorvig, 2007). However, when subtracting the cost of drainage, the overall cost for this pavement may actually be lower than flexible pavement. The crucial element in maintaining permeable pavement is mowing the grass since tall grass matted down by vehicles will decrease its porosity.

From the interviews conducted, it was found that IBS StormPav pavement has yet to be implemented in Malaysia. Therefore, its performance level and durability are not yet known. However, from the on-site data collection, this pavement's surface temperature is notably cooler than that of asphalt pavement. It behaves similarly to normal concrete pavement since the materials that make up these pavements are the same, although IBS StormPav uses a higher grade of concrete. IBS StormPav can be maintained by simply removing any sediments such as dirt, mud, and dust inside the precast unit. Since the height of the pavement unit is known, the level of sediment can be easily monitored using a measuring tape. If the height of the sediment indicates that the IBS StormPav needs to be cleaned, then an air compressor or hot air lance is inserted into the openings of the pavements to suck out dust, mud, and debris from the pavement unit. Hence, the maintenance cost will be very low.

\subsection{Summary}

The summarization of the data analysis for this study is presented in Tables 1 and 2. Table 1 summarizes the surface temperature data for all types of pavements. In terms of heat absorption, the pavements are ordered from greatest to least: asphalt, porous/permeable, IBS StormPav, and PCC. It has been proven that asphalt pavement and other dark surfaces in urban environments are the primary sources of the UHI phenomenon. Since asphalt pavement has a lower albedo than other type of pavements, it absorbs the sun's radiation the most. PCC and IBS StormPav pavements will always have lower surface temperatures than asphalt pavement due to their higher albedo values. In addition to exhibiting a lower albedo value than asphalt pavement, permeable pavement also undergoes evapotranspiration due to its grass surface. The process provides a cooling effects as water is evaporated from the soil and plants. Plants also transpire by gaining water through roots and releasing it through the leaves (Julie et al., 2014). The solar energy that would heat the pavement surfaces is instead used in the evapotranspiration process, keeping its surface and the surrounding air relatively cool.

Table 1 Summarization of surface temperature data for the pavements

\begin{tabular}{|c|c|}
\hline Pavement Types & Findings \\
\hline Asphalt & $\begin{array}{ll} & \text { Absorbs more heat than the other types of pavements } \\
\text { - } & \text { Has lower albedo than concrete pavement } \\
\text { - } & \text { Has higher density than concrete pavement } \\
\text { - } & \text { Highest recorded temperature is } 47.3^{\circ} \mathrm{C}\end{array}$ \\
\hline PCC & $\begin{array}{l}\text { - } \text { Absorbs less heat than asphalt pavement } \\
\text { - Has higher albedo and reflective properties than asphalt } \\
\text { pavement } \\
\text { - } \text { Has lower density than asphalt pavement } \\
\text { - } \text { Highest recorded temperature is } 38.1^{\circ} \mathrm{C}\end{array}$ \\
\hline Porous/Permeable & $\begin{array}{l}\text { - } \text { Absorbs less heat than asphalt pavement } \\
\text { - } \quad \text { Permits water to filter into the ground } \\
\text { - } \quad \text { Undergoes higher convective losses } \\
\text { - } \quad \text { Highest recorded temperature is } 39.8^{\circ} \mathrm{C}\end{array}$ \\
\hline IBS StormPav & $\begin{array}{ll}\text { - } & \text { Absorbs less heat than asphalt pavement } \\
\text { - } & \text { Possesses similar characteristics to normal concrete pavement } \\
\text { - } & \text { Highest recorded temperature is } 38.5^{\circ} \mathrm{C}\end{array}$ \\
\hline
\end{tabular}


Table 2 summarizes the performance and maintenance of pavements as elaborated in Section 3.2 for easier comparison between pavement types. It has been found that asphalt pavement is the most generic type of pavement used in Malaysia because of its lower construction cost. Although the installation and maintenance is inexpensive, the frequency of maintenance is higher than for other types of pavements. Therefore, the total cost of this pavement throughout its lifespan could be higher than for other types. Additionally, asphalt pavement has more detrimental effects on the environment, making it less environmentally friendly. Concrete pavement is typically only used to construct walkways or pedestrian pathways. Less maintenance is required for concrete pavement over its lifetime, and it lasts longer than asphalt pavement. This pavement is more environmentally friendly than asphalt because its material is $100 \%$ recyclable. Besides that, its rigidity lowers vehicles' fuel usage and associated emissions. The study conducted by Cement Association of Canada (2009) has found that the potential truck fuel savings is $15 \%$ more when operating on concrete pavement than asphalt pavement. Permeable pavement is usually used in parking areas and pathways. It reduces the risk of hydroplaning and the maintenance is relatively minimal after installation. Once or twice a year, sediment deposition should be removed through vacuum sweeping. For IBS StormPav, an air compressor or hot air lance can be used to suck out dust, mud, and debris from the pavement unit. Thus, the maintenance cost will be very low. This pavement helps reduce runoff and recharges groundwater. It is also predicted to be highly durable.

Table 2 Summarization of pavement performance and maintenance

\begin{tabular}{|c|c|}
\hline Pavement Types & Performance and Maintenance \\
\hline Asphalt & $\begin{array}{l}\text { - Used on } 90 \% \text { of new roads in Sarawak } \\
\text { - Inexpensive to install and maintain } \\
\text { - Needs resurfacing every five years, depending on road conditions. } \\
\text { - } \text { Maintained by PPES Works, CMS, and others } \\
\text { - Hazardous emissions from mixing, heating, and placement } \\
\quad \text { due to its imperviousness }\end{array}$ \\
\hline PCC & $\begin{array}{l}\text { - } \text { Rarely used for main roads in Sarawak } \\
\text { - Implemented as walkways or pedestrian pathways } \\
\text { - Less maintenance over its lifetime } \\
\text { - Minimizes the potential for potholes } \\
\text { - } 100 \% \text { recyclable, eliminating the need to dispose of old material } \\
\text { - Significant fuel savings and associated emissions reductions }\end{array}$ \\
\hline Porous/Permeable & $\begin{array}{l}\text { - Rarely used for main roads in Sarawak } \\
\text { - Commonly used in parking areas or pathways, seldom for highways } \\
\text { - Offers better traction and exhibits less risk of hydroplaning } \\
\text { - Relatively minimal maintenance after installation } \\
\text { - Needs monitoring and vacuum sweeping of sediment deposits (once or twice a year) }\end{array}$ \\
\hline IBS StormPav & $\begin{array}{l}\text { - Needs an air compressor or hot air lance to suck out dust, mud, and debris } \\
\text { - Reduces runoff and recharges groundwater } \\
\text { - Performance level and durability unknown (predicted to be highly durable) }\end{array}$ \\
\hline
\end{tabular}

\section{CONCLUSION}

In conclusion, since Malaysia is experiencing rapid urbanization, it is extremely important that the issue of UHI be addressed before the country experiences levels similar to Tokyo, Thailand, Paris, and other cities. Some strategies have been outlined to mitigate the UHI phenomenon:

- Implementation of green walls

- Implementation of cool/green roofs

- Minimizing the environmental impact of asphalt pavement

- Planting trees and vegetation 
- Implementation of permeable pavement or surfaces

- Implementation of cool pavement

One of limitations of this study is that the interviewees were not familiar with the new, green pavement known as IBS StormPav. Information on its actual performance and durability are not yet known since this pavement has yet to be implemented. Therefore, there is no data that can support the theories about this pavement. Besides that, the surface temperature data for the IBS pavement could be more accurate if thermocouples were utilized. An accurate temperature can be obtained from inside the pavement by installing thermocouples on the inner top and bottom of the pavement. However, the surface temperature obtained from the outside of this pavement using ThermaCam is also sufficient and representative of the nature of the pavement. The recorded temperatures prove that this pavement absorbs less heat than asphalt and has similar characteristics to normal concrete pavement.

For future research, investigation of the thermal behavior and heat impact of the vertical surfaces of buildings should be conducted regarding their mitigation or intensification factors on UHI. This study will be based on the materials of buildings that are typically used in Malaysia: concrete, brick, white concrete tiles, and granite. This study could be implemented in the hottest area of Kuching. The data collection will include the hourly surface temperatures for 12 hours using ThermaCam and the air temperature using an anemometer. This future study can improve the knowledge and understanding of other factors that contribute to the UHI phenomenon.

\section{ACKNOWLEDGEMENT}

The authors wish to thank the Faculty of Engineering (Universiti Malaysia Sarawak) for the opportunity to undertake this project, Jabatan Kerja Raya Sarawak and Jabatan Kerja Raya Batu Lintang for the support to complete this research.

\section{REFERENCES}

Akbari, H., Rose, L.S., 2001. Characterizing the Fabric of the Urban Environment: A Case Study of Metropolitan Chicago, Illinois. Lawrence Berkeley National Laboratory, Berkeley, CA, USA

American Association of State Highway and Transportation Officials, 2007. AASHTO Maintenance Manual for Roadways and Bridges. American Association of State Highway and Transportation Officials, Washington, DC, USA

American Concrete Pavement Association, 2009. Hot Pavement. Available Online at http://www.pavements4life.com/qds/environment_1heatisland.asp, Accessed on February 20,2016

Asaeda, T., Ca, V.T., Wake, A., 1996. Heat Storage of Pavement and Its Effect on the Lower Atmosphere. Atmospheric Environment, Volume 30(3), pp. 413-427

Brontowiyono, W., Lupiyanto, R., Wijaya, D., Hamidin, J., 2011. Urban Heat Islands Mitigation by Green Open Space (GOS) Canopy Improvement: A Case of Yogyakarta Urban Area (YUA), Indonesia. International Journal of Technology, Volume 2(3), pp. 207-214

Calkins, M., 2012. The Sustainable Sites Handbook: A Complete Guide to the Principles, Strategies, and Best Practices for Sustainable Landscapes. John Wiley \& Sons, Hoboken, New Jersey, USA

Cement Association of Canada, 2007. Concrete Thinking in Transportation Solutions. Cement Association of Canada, Ottawa, Canada 
Cement Association of Canada, 2009. Cement and Concrete Industries Contribution to Climate Change Mitigation. Vancouver, British Columbia

Delatte, N., 2007. Concrete Pavement Design, Construction, and Performance. CRC Press, Boca Raton, Florida, USA

Dobos, E., 2003. Albedo. Marcel Dekker, Inc., Miskolc, Hungary

Gartland, L.M., 2012. Heat Islands: Understanding and Mitigating Heat in Urban Areas. Earthscan, London, UK

Ibrahim, S.H., Baharun, A., Nawi, M.N.M., Junaidi, E., 2014. Analytical Studies on Levels of Thermal Comfort in Typical Low-income Houses Design. Unimas e-Journal of Civil Engineering, Volume 5(1), pp. 28-33

Jabatan Kerja Raya Malaysia, 1988. Standard Specification for Road Works (JKR/SPJ/1988). Jabatan Kerja Raya Malaysia, Kuala Lumpur, Malaysia

Julie, F., Gail, H., Sue, M., John, R., 2014. A Guide to Green Roofs, Walls and Facades in Melbourne and Victoria, Australia. State of Victoria, Melbourne, Australia

Juliet, D.M., Ossen, D.R., 2009. The Effect of Water on Outdoor Paved Surfaces: A Strategy to Mitigate Urban Heat Island. University Teknologi Malaysia, Johor Bahru, Malaysia

Katzschner, L., 2009. Urban Climate in Dense Cities. In: Designing High-density Cities for Social and Environmental Sustainability, Ng, E., (ed.), Earthscan, London, UK, pp. 71-78

Li, H., 2015. Pavement Materials for Heat Island Mitigation: Design and Management Strategies. Butterworth-Heinemann, Waltham, Massachusetts, USA

Lin, T., Matzarakis, A., Hwang, R., 2010. Shading Effect on Long-term Outdoor Thermal Comfort. Building and Environment, Volume 45(1), pp. 213-221

Ping, B.Y., 2016. Personal Interview, Conducted on March 9, 2016

Rose, L.S., Akbari, H., Taha, H., 2003. Characterizing the Fabric of the Urban Environment: A Case Study of Greater Houston, Texas. Lawrence Berkeley National Laboratory, Berkeley, California, USA

Rosenfeld, A.H., Akbari, H., Bretz, S., Fishman, B.L., Kurn, D.M., Sailor, D.J., Taha, H., 1995. Mitigation of Urban Heat Islands: Materials, Utility Programs, Updates. Energy and Buildings, Volume 22(3), pp. 255-265

Santamouris, M., 2013. Using Cool Pavements as a Mitigation Strategy to Fight Urban Heat Island - A Review of the Actual Developments. Renewable and Sustainable Energy Reviews, Volume 26, pp. 224-240

Sarat, A.A., Eusuf, M.A., 2012. An Experimental Study on Observed Heating Characteristics of Urban Pavement. Journal of Surveying, Construction and Property, Volume 3(1), pp. 1-12

Stempihar, J.J., Pourshams-Manzouri, T., Kaloush, K.E., Rodezno, M.C., 2011. Porous Asphalt Pavement Temperature Effects for Urban Heat Island Analysis. 2012 Annual Meeting of the Transportation Research Board, Tempe, Arizona, USA

Swee, R.T.K., 2016. Personal Interview, Conducted on March 2, 2016

Thompson, J.W., Sorvig, K., 2007. Sustainable Landscape Construction: A Guide to Green Building Outdoors. $2^{\text {nd }}$ ed. Island Press, Washington, DC, USA

Virginia Water Resources Research Center, 2011. Virginia Deq Stormwater Design Specification No. 7: Permeable Pavement. Available Online at http://www.vwrrc.vt.edu/swc/NonPBMPSpecsMarch11/VASWMBMPSpec7PERMEABL EPAVEMENT.html, Accessed on February 25, 2016 